Original Research Paper

\title{
Experimental Investigation of Limonene-based Environmental-Friendly Emulsion Drilling Mud
}

\author{
${ }^{1}$ Olaitan Oluwaseum Micheal, ${ }^{1}$ Orodu Oyinkepreye David and ${ }^{2}$ Ehinmowo Adegboyega Bolu \\ ${ }^{I}$ Department of Petroleum Engineering, Covenant University, Canaan Land, Ota, Nigeria \\ ${ }^{2}$ Department of Chemical and Petroleum Engineering, University of Lagos, Lagos, Nigeria
}

\section{Article history}

Received: 04-05-2017

Revised: 06-05-2017

Accepted: 12-06-2017

Corresponding Author: Orodu Oyinkepreye David Department of Petroleum Engineering, Covenant University, Canaan Land, Ota, Nigeria

Email:

oyinkepreye.orodu@covenantu niversity.edu.ng;

preye.d.orodu@gmail.com

\begin{abstract}
The use of emulsion drilling mud in the oil and gas industry has gained wide acceptance. However, the disposal of drill cuttings and the waste of such emulsion drilling mud usually poses environmental concern. Hence, there is the need to seek oil from biodegradable sources as an alternative to the current conventional diesel oil which constitute environmental threat. In this study, limonene obtained from dried peel of sweet orange was used as the dispersed phase in the formulation of nanomodified emulsion drilling mud. A Design Of Experiment (DOE) approach was employed to investigate the extraction of limonene and the results analysed. Three different mud samples were formulated; the conventional water-based drilling mud, nano-modified emulsion drilling mud with diesel oil and limonene as the dispersed phase respectively. The rheological properties, density, sand content, $\mathrm{PH}$ and filtration loss of the formulated mud samples were tested and compared. The results of the experiment showed that the formulated nano-modified emulsion drilling mud with limonene as the dispersed phase followed Herschel-Bulkley rheological Model with low gel strength and yield point which are desirable mud property for turbulent flow at low pump pressure for effective hole cleaning. Also, there is reduction in filtration loss and mud cake compared to the conventional water-based drilling mud which will lead to reduction in torque and drag, reduction in pipe sticking, reduction in hole enlargement and less bit balling.
\end{abstract}

Keywords: Design of Experiment, Limonene, Emulsion Mud System, Rheology, Filtration Loss

\section{Introduction}

Drilling mud is a very important element of any drilling operation. Within the early days of rotary drilling, the primary function of drilling mud was to bring the drill cutting from the bottom of the hole to the surface. Today it is recognised that drilling mud has many more important functions (Caenn and Chillingar, 1996; Barlow and Kingston, 2001). Drilling mud must be able to suspend cuttings by removing them from the bottom of the hole and the well bore and release them at the surface, cool and lubricate the drill bit and drill string, control formation pressure and maintain wellbore stability by minimizing formation/fluid interactions and sealing the wall of the bore hole with an impermeable cake, control corrosion of the metal components of the drilling tools, casing and rig facilities that are exposed to the corrosive marine environment, maximize drilling penetration rates, facilitate cementing and completion, minimize impact on the environment.

Oil based mud is a drilling fluid with diesel, biodiesel or mineral biodiesel as the main component. Commonly, oil based mud is employed in drilling hard shales, high pressure High Temperature wellbore, sour borehole environments. However, owing to the nephrotoxic and high aromatic content, oil based mud cannot be use easily in any geographical location, especially for environmentally sensitive offshore areas (Amanullah, 2005).

In response to the nonbiodegradability of diesel oil on the surroundings and on the ozonosphere, researches and reviews have gone on in the past two to three decades and have propose mud formulations based on the 
utilization of oils from plant as an alternative to diesel oil. Plant oils gain more popularity within the raw materials market as an alternative to diesel oil over the years. Common among the plant oils being: Palm oil, Sesame oil, Jathropha oil, Rapeseed oil, Cottonseed oil, Mahua oil, Soya bean oil, etc. This begets the importance of agro-allied intervention within the oil and gas industry (Dosunmu and Ogunrinde, 2010; Fadairo et al., 2012a). Also, the volatile oil of Nigerian sweet orange peels was extracted and put through some chemical characterization in order to establish its raw material potential (Ezejiofor et al., 2011; Njoku and Evbuomwan, 2014).

Using nanoparticles as an additive and exploring tragacanth gum and Carboxymethyl Cellulose (CMC) in the formulation of oil-in-water emulsion has shown improved rheological and filtration properties, thermal stability and minimised formation damage (Jha et al., 2015; Yue and Ma, 2008; Fadairo et al., 2012b; Al-Riyamy and Sharma, 2004; Paswan et al., 2016; Nasser et al., 2013; Kasiralvalad, 2014). Despite the advances in the formulation of emulsion drilling fluid, there appears to be limited knowledge on the nanomodified biodegradable emulsion drilling fluid. Hence, the main objective of this research work is to formulate nano-modified emulsion drilling mud with limonene and diesel oil as the dispersed phase and, to test the rheological and filtration loss properties of the formulated drilling mud samples.

\section{Materials and Methods}

This section describes the materials used and methodology adopted to achieve the objectives set out for this research work. The experimental work was divided into two parts: The first part dealt with the extraction of the essential oil (limonene) from dried sweet orange peel while the second part focused on using the extracted oil from dried sweet orange peel to formulate oil-in-water emulsion drilling mud with silicon oxide nanoparticle as an additive. The experimental procedures are well explained. Figure 1 shows the overview of this section.

Design of Experiments (DOE) was applied, this is a pattern of gathering pragmatic knowledge, i.e., information based on the analysis of empirical data instead of hypothetical models. DOE approach offers a robust technique to expeditiously design industrial experiments that will improve understanding of the interaction between variables and the desired performance characteristics of a product or a process. Compared to the normal experimental approach, which varies only one factor at a time, the performance map and prediction capability of DOE make both the local and global optimum achievable (Anderson and Whitcomb, 1998).
Factorial design, an experimental design approach is used in this study for effectively carrying out an optimised evaluation of the various factors that influence the maximum extraction of limonene. For this, a 2-level and six-factor design is used for the investigation of limonene extraction and 2-level and 2-factor design for the evaluation of the nano-modified oil-in-water emulsion based drilling mud. A total of $64\left(2^{6}=64\right)$ experimental runs were performed for the extraction of limonene with the factors of interest being quantity of pulverised orange peel with high and low values of 200 and $400 \mathrm{~g}$, volume of hexane with high and low values of 900 and $400 \mathrm{~mL}$, heating temperature with high and low values of 130 and $0^{\circ} \mathrm{C}$, heating time with high and low values of 60 and $0 \mathrm{~min}$, distillation temperature with high and low values of 104 and $78^{\circ} \mathrm{C}$ and distillation time whose high and low values were 60 and 40 min respectively. The response was the yield. Also, a total of $4\left(2^{2}=4\right)$ experimental runs were performed for the formulation of nano-modified oil-inwater emulsion based drilling mud using diesel as a control and the extracted limonene with the factors of interest being the volume of the limonene with high and low values of 20 and $10 \mathrm{~mL}$ and the quantity of silicon oxide nanoparticle used as additive with high and low values of 10 and $5 \mathrm{~g}$ respectively.

The basic starting point is the acquisition of orange (Citrus sinensis). Orange peels were obtained locally from the South-West region of Nigeria. The collected sweet orange peels were washed and air dried at room temperature. The dried peels were then grinded to powder using an electric grinding machine. The grounded peels were then stored in a sample nylon. The reagents used are Normal hexane (Laboratory reagent grade), Sodium Hydroxide (reagent grade, 98\% assay), Bentonite (API Specification 13A), Barite, Carboxymethyl cellulose (CMC), Silicon oxide nanoparticle, Primary emulsifier (GLO PEMUL 1000), Secondary emulsifier (GLO SEMUL 1000), Diesel oil and de-ionized water.

Standard drilling fluid laboratory equipment were used. Amongst these are laboratory oven. HPHT filter press, viscometer (OFITE 800 model), OFITE sand content kit, chemical balance, resistivity meter, mud balance and $\mathrm{H} 12211 \mathrm{Ph} / \mathrm{ORP}$ meter.

The limonene extraction was carried out using two different methods; soxhlet extraction and leaching. Figure 2 shows the flow chart for the extraction of limonene.

A standard water-based drilling mud sample were initially formulated with composition and mixing order shown in Table 2 and its mud properties tested without the addition of nanoparticle, emulsifier and oil. This was then followed by the formulation of eight other nanomodified oil-in-water emulsion drilling mud samples with four of the mud samples having diesel oil added as the dispersed phase while the other four samples have 
the extracted limonene as the dispersed phase following the design of experiment shown in Table 1. Also, the composition and mixing order of the nano-modified oil- in-water emulsion drilling mud are shown in Table 3. The samples having diesel oil added to it as the dispersed phase are used as control.

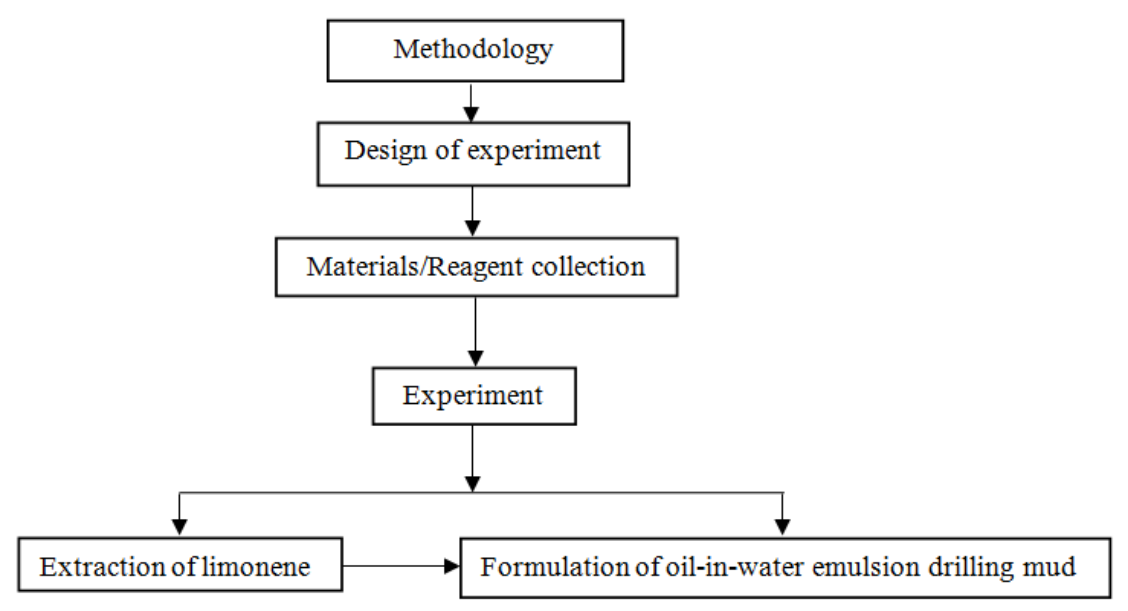

Fig. 1. Diagram showing methodology structure

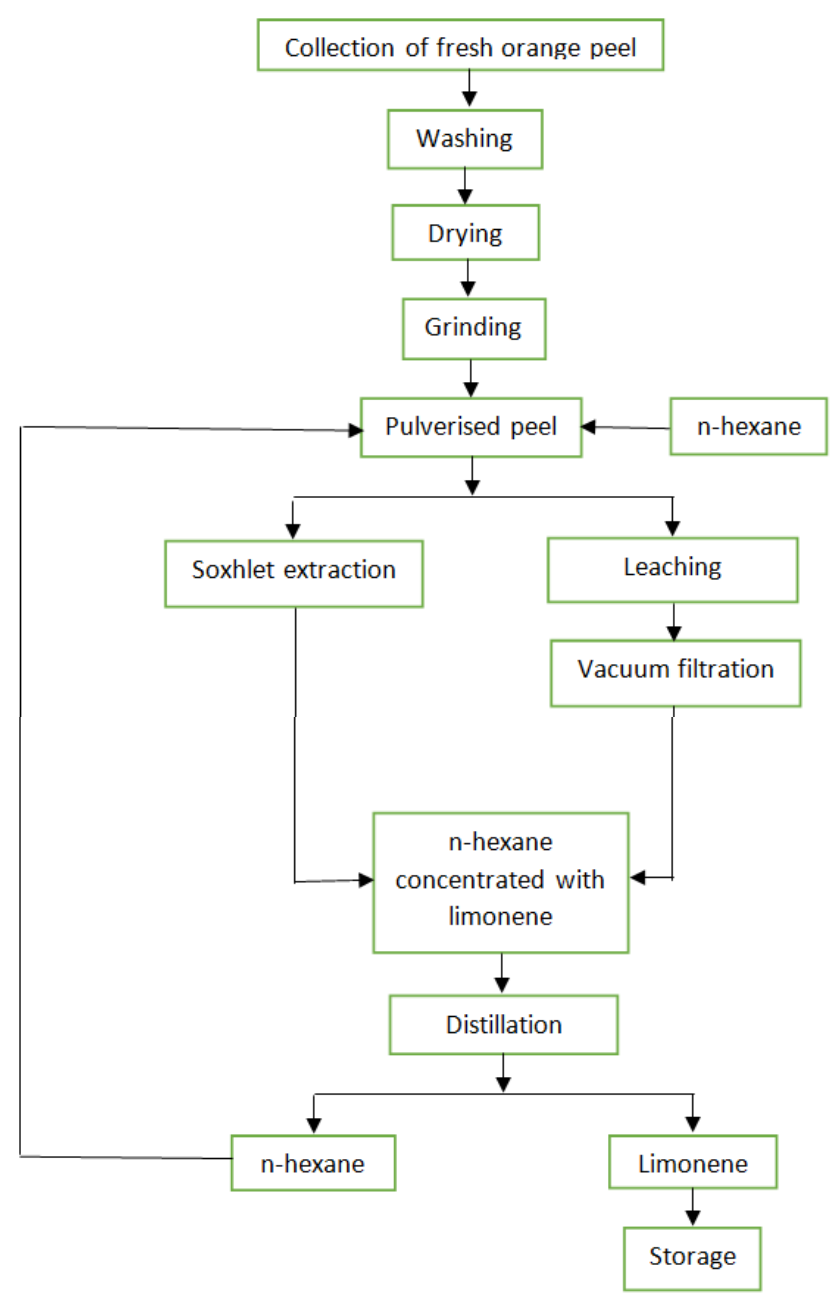

Fig. 2. Flow chart for limonene extraction 
Table 1. Design of experiment for nano-modified oil-in-water emulsion drilling mud

\begin{tabular}{lllllc}
\hline StdOrder & RunOrder & Centerpt & Blocks & Vol of Limonene/Diesel $(\mathrm{ml})$ & Qty of Nanoparticle $(\mathrm{g})$ \\
\hline 2 & 1 & 1 & 1 & 20 & 5 \\
4 & 2 & 1 & 1 & 20 & 10 \\
3 & 3 & 1 & 1 & 10 & 10 \\
1 & 4 & 1 & 1 & 10 & 5 \\
\hline
\end{tabular}

Table 2. Composition of water-based drilling mud

\begin{tabular}{lccc}
\hline Mud component & Vol/Qty & Mixing duration (mins) & Mixing order \\
\hline Water $(\mathrm{ml})$ & 400.00 & - & 1 \\
Bentonite $(\mathrm{g})$ & 20.00 & 5 & 2 \\
$\mathrm{CMC}(\mathrm{g})$ & 0.30 & 5 & 3 \\
$\mathrm{NaOH}(\mathrm{g})$ & 0.20 & 5 & 4 \\
Barite $(\mathrm{g})$ & 5.00 & 10 & 5 \\
\hline
\end{tabular}

Table 3. Composition of nano-modified oil-in-water emulsion drilling mud

\begin{tabular}{llcc}
\hline Mud component & Vol/Qty & Mixing duration (mins) & Mixing order \\
\hline Water (ml) & $375 / 375 / 385 / 385$ & - & 1 \\
Primary emulsifier (ml) & 3 & 5 & 2 \\
Secondary emulsifier (ml) & 2 & 5 & 3 \\
CMC (g) & 0.30 & 5 & 4 \\
Limonene/diesel oil (ml) & Refer to Table 1 & 10 & 5 \\
Bentonite & $15 / 10 / 10 / 15$ & 5 & 6 \\
NaOH $(\mathrm{g})$ & 0.20 & 5 & 7 \\
Silicon oxide $(\mathrm{g})$ & Refer to Table 1 & 5 & 8 \\
Barite $(\mathrm{g})$ & 5 & 10 & 9
\end{tabular}

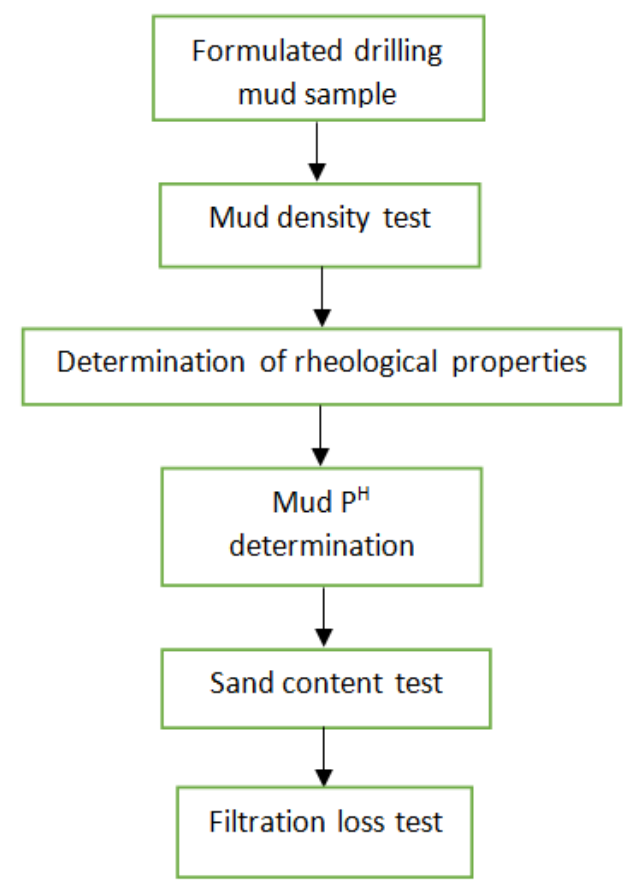

Fig. 3. Flow chart for the determination of the formulated drilling mud properties

Figure 3 shows the flow chart for the determination of the properties of the formulated drilling mud.

\section{Results and Discussion}

\section{Extraction of Limonene}

The full experimental runs for the design of experiment for the extraction of limonene from dried peels of sweet orange is 64 runs. The experiment was designed with the factors of interest being quantity of pulverised orange peel, volume of hexane, heating temperature, heating time, distillation temperature, distillation time and yield was the response variable.

The normal plot of the effects (Fig. 4) shows that quantity of the pulverised peel has the largest effect on yield of limonene, next to it is volume/concentration of the hexane. The distillation temperature has the least effect on the yield of limonene. This shows an increase in the quantity of pulverised peel and volume/concentration of hexane will result in an increase in the yield of limonene, hence a linear relationship exists between the quantity of pulverised peel and the yield of limonene.

The pareto chart of the effects (Fig. 5) shows that quantity of the pulverised peel has the largest effect on yield of limonene, next to it is volume/concentration of the hexane. The distillation temperature has the least effect on the yield of limonene. This shows an increase in the quantity of pulverised peel and volume/concentration of hexane will result in an increase in the yield of limonene. 


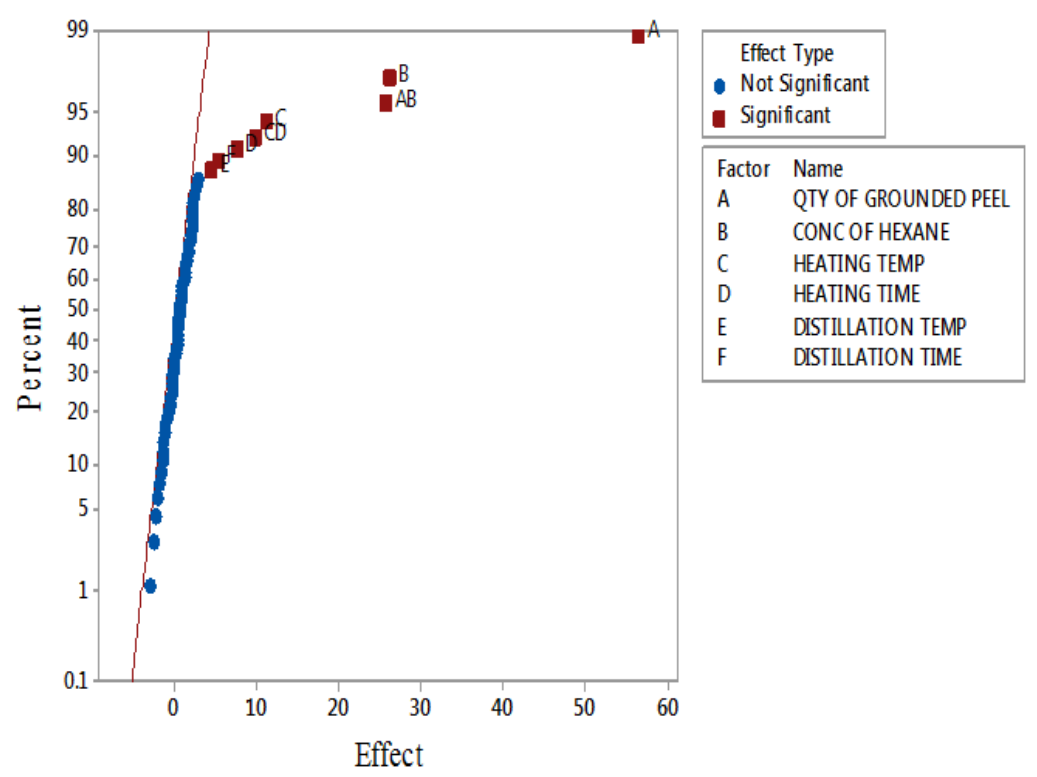

Lenth's PSE $=1.75781$

Fig. 4. Normal plot of the effects (response is YIELD, $\alpha=0.05$ )

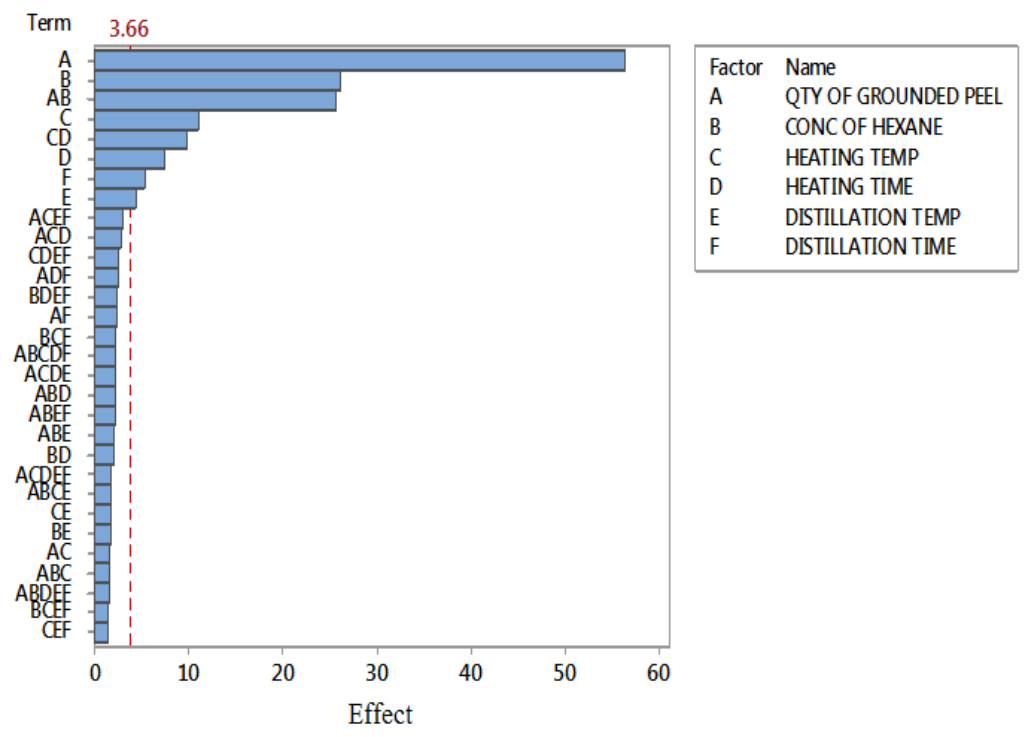

Lenth's PSE $=1.75781$

Fig. 5. Pareto chart of the effects (response is YIELD, $\alpha=0.05$, only 30 effects shown)

Table 4. Mud density and specific gravity measurements

\begin{tabular}{lll}
\hline Sample & Density (ppg) & Specific gravity \\
\hline Water based mud & 8.5 & 1.03 \\
Runorder1 (diesel) & 7.4 & 0.94 \\
Runorder1 (limonene) & 6.8 & 0.81 \\
Runorder2 (diesel) & 7.9 & 0.95 \\
Runorder2 (limonene) & 7.0 & 0.84 \\
Runorder3 (diesel) & 7.5 & 0.90 \\
Runorder3 (limonene) & 6.9 & 0.83 \\
Runorder4 (diesel) & 7.4 & 0.94 \\
Runorder4 (limonene) & 7.1 & 0.85 \\
\hline
\end{tabular}




\section{Investigation of Densities of Formulated Drilling Mud}

Mud density is the weight per unit volume of mud and is used for providing hydrostatic pressure for maintaining well control during drilling operation. It is usually reported in ppg. The results obtained from measurements of density using the mud balance are shown in Table 4.

The bar chart in Fig. 6 shows that the water based mud is denser than the nano-modified oil-in-water emulsion drilling mud. It can also be seen from Table 4 that the nano-modified oil-in-water emulsion drilling mud samples with limonene as the dispersed phase compare well with the samples with diesel as the dispersed phase. The formulated nano-modified oil-inwater emulsion drilling mud has the highest density when $10 \mathrm{~mL}$ of limonene was used as the dispersed phase and $5 \mathrm{~g}$ of silicon oxide nanoparticle used all at the same quantity of barite.

\section{Rheological Properties}

The basic reason for studying the rheological properties, as well as the filtration properties, fluid loss and filter cake of the formulated water-based drilling mud and the nano-modified oil-in-water emulsion drilling mud samples as the basis for comparison. Also, the relevance these properties offer to the overall drilling mud performance. The yield point is used to measure the ability of a mud to elevate cuttings out of the annulus. A high yield point implies a non-Newtonian fluid; one that carries cuttings better than a mud of comparable density however with lower yield point. In addition, frictional pressure loss is directly related with the yield point. It is vital to state here that to a fault high yield point leads to pressure losses while the drilling mud is being circulated. Table 5 shows the viscometer speed in RPM and the corresponding dial reading. Equations 1 to 3 are used to calculate the rheological parameters:

Plastic viscosity, $P V(c p)=$

$\mu_{\rho}=300 \frac{\theta_{N}}{N}-\frac{300 \tau_{y}}{N}=\theta_{\gamma 600 R P M}-\theta_{\gamma 300 R P M}$

where the viscometer readings denoted as $N=300,600$ $\mathrm{RPM}), \mu_{\rho}=$ Plastic Viscosity (PV):

Yield point $\left(I b / 100 f^{2}\right), Y P=\tau_{y}=\theta_{\gamma 300 R P M}-P V$

where the yield point is denoted by $\tau_{y}$ :

Apparent viscosity $=\frac{1}{2} \theta_{\gamma 600 R P M}$

Plastic viscosity can be thought of as part of the flow resistance caused my mechanical friction (i.e., solids content). Yield point is that component of resistance caused by electrochemical attraction within the mud while it is flowing.

Table 6 shows the rheological parameters calculated using equations 1 to 3 of the formulated mud samples at different RunOrder. Mud samples formulated with limonene as the dispersed phase compare well with that of diesel.

Table 5. Viscometer Speed and the corresponding Dial reading for the mud samples

\begin{tabular}{|c|c|c|c|c|c|c|c|c|c|}
\hline \multirow[b]{2}{*}{ RPM } & \multicolumn{9}{|l|}{ Dial Reading } \\
\hline & Water based mud & Diesel 1 & Limonene 1 & Diesel 2 & Limonene 2 & Diesel 3 & Limonene 3 & Diesel 4 & Limonene 4 \\
\hline 600 & 25 & 19 & 25 & 14 & 12 & 13.0 & 10 & 14.0 & 18 \\
\hline 300 & 17 & 14 & 19 & 10 & 8 & 9.0 & 8 & 10.0 & 13 \\
\hline 200 & 14 & 12 & 16 & 9 & 6 & 8.0 & 6 & 8.0 & 11 \\
\hline 100 & 10 & 10 & 12 & 7 & 5 & 6.0 & 5 & 6.5 & 9 \\
\hline 60 & 8 & 9 & 10 & 6 & 4 & 5.5 & 4 & 5.5 & 8 \\
\hline 30 & 6 & 8 & 8 & 5 & 3 & 4.5 & 3 & 4.5 & 7 \\
\hline 6 & 4 & 7 & 6 & 4 & 2 & 4.0 & 2 & 4.0 & 5 \\
\hline
\end{tabular}

Table 6. Rheological parameters of the formulated drilling mud

\begin{tabular}{|c|c|c|c|c|c|c|c|c|c|}
\hline \multirow[b]{2}{*}{ Mud properties } & \multirow{2}{*}{$\begin{array}{l}\text { Water } \\
\text { based }\end{array}$} & \multicolumn{2}{|c|}{ Runorder1 } & \multicolumn{2}{|c|}{ Runorder2 } & \multicolumn{2}{|c|}{ Runorder3 } & \multicolumn{2}{|c|}{ Runorder4 } \\
\hline & & Diesel & Limonene & Diesel & Limonene & Diesel & Limonene & Diesel & Limonene \\
\hline Gel strength $10 \mathrm{sec}, \mathrm{lb} / 100 \mathrm{ft}^{2}$ & 3.0 & 10.0 & 5.0 & 5 & 2 & 5.0 & 3 & 6 & 8 \\
\hline Gel strength $10 \mathrm{~min}, \mathrm{lb} / 100 \mathrm{ft}^{2}$ & 30.0 & 20.0 & 33.0 & 12 & 10 & 9.0 & 10 & 15 & 22 \\
\hline Plastic viscosity, $\mathrm{cp}$ & 8.0 & 5.0 & 6.0 & 4 & 4 & 4.0 & 2 & 4 & 5 \\
\hline Yield point, $\mathrm{lb} / 100 \mathrm{ft}^{2}$ & 9.0 & 9.0 & 13.0 & 6 & 4 & 5.0 & 6 & 6 & 8 \\
\hline Apparent viscosity, cp & 12.5 & 9.5 & 12.5 & 7 & 6 & 6.5 & 5 & 7 & 9 \\
\hline
\end{tabular}




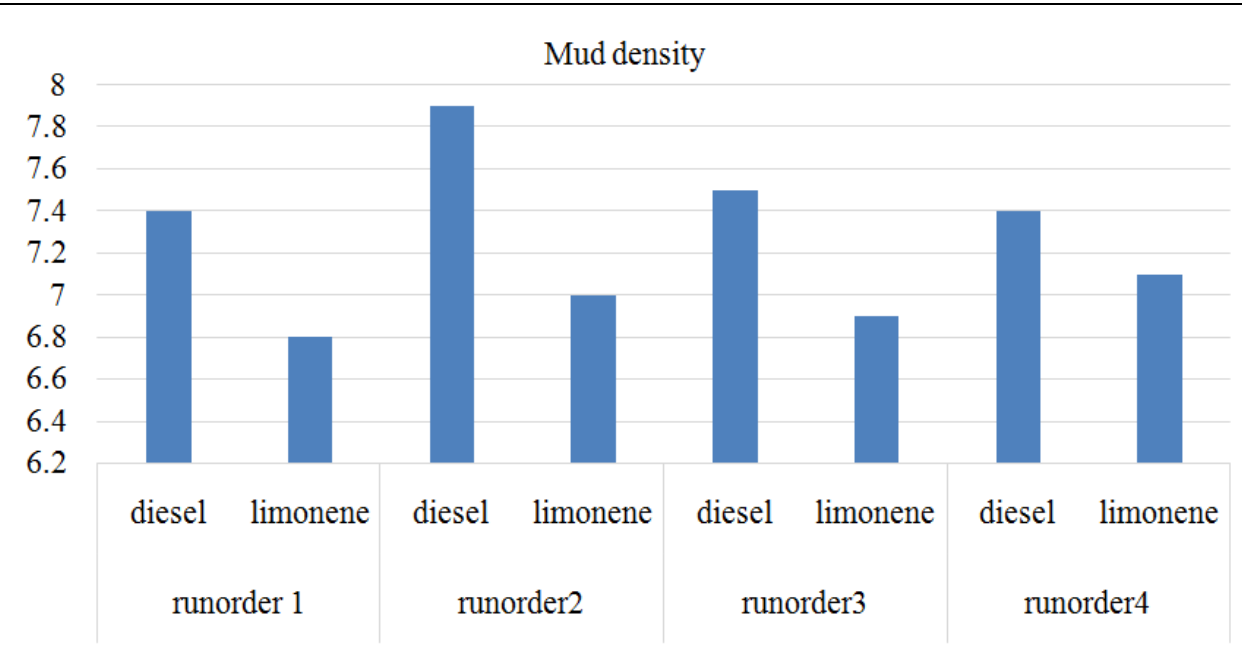

Fig. 6. Mud density

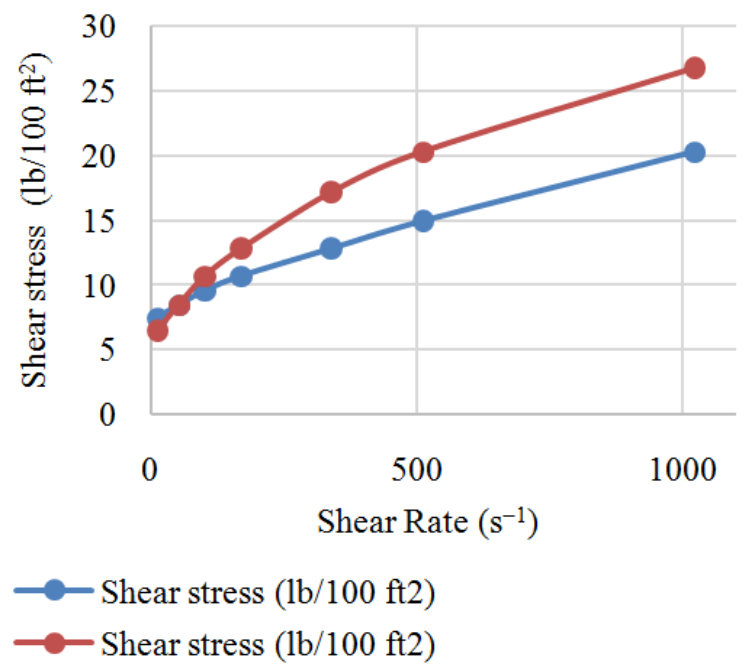

Fig. 7. Shear Stress Vs Shear Rate Curve for Runorder1

Another vital drilling mud property is the gel strength, because it demonstrates the ability of the drilling mud to suspend weighting material and drilled cuttings when drilling mud circulation is ceased. The formulation using the runorder1 with limonene as the dispersed phase has the highest gel strength as seen in Table 6 but still within the desirable range.

Plastic viscosity is that part of the opposition to flow caused by mechanical friction. The friction is caused by: Viscosity of the fluid phase, solids concentration and shape and size of solids.

It can be inferred that decreasing the solid concentration, shape and size of solids and reducing the viscosity of the fluid phase will reduce the plastic viscosity of the drilling mud. Formulation using runorder3 with limonene as the dispersed phase has the lowest value plastic viscosity while formulation using runorder1 with limonene as the dispersed phase has the highest value of plastic viscosity as shown in Table 6.

The yield point is the initial opposition to flow caused by electrochemical forces between the particles. This electrochemical force is because of charges on the surface of the particles dispersed in the fluid phase. Formulation using runorder2 with limonene as the dispersed phase has the lowest yield point while formulation using runorder1 with limonene as the dispersed phase has the highest yield point as shown in Table 6 .

Apparent viscosity is the reflection of plastic viscosity and the yield point combined. An increase in the either plastic viscosity or yield point or both will cause an increase in the apparent viscosity as seen from Table 6. Formulation using runorder1 with limonene as the dispersed phase has the highest value of apparent viscosity which reflects the value of the plastic viscosity and yield point at the same runorder 1 .

Figure 7 to 10 are curves that depict the relationships between the shear stress and shear rate. It can be seen from the curves that the formulated drilling samples have similar rheological properties and are similar to the Herschel-Bulkley Model. They also belong to the non-Newtonian fluid category. The rheological properties of this work compare well with results of a similar work using Jathropha oil as the dispersed phase in the formulation of oil-in-water emulsion drilling mud by Paswan et al. (2016).

\section{$P^{H}$ Test of Formulated mud Samples}

The results of the $\mathrm{P}^{\mathrm{H}}$ test carried out on both the formulated water-based and nano-modified oil-in-water emulsion drilling mud are shown in Table 7. 


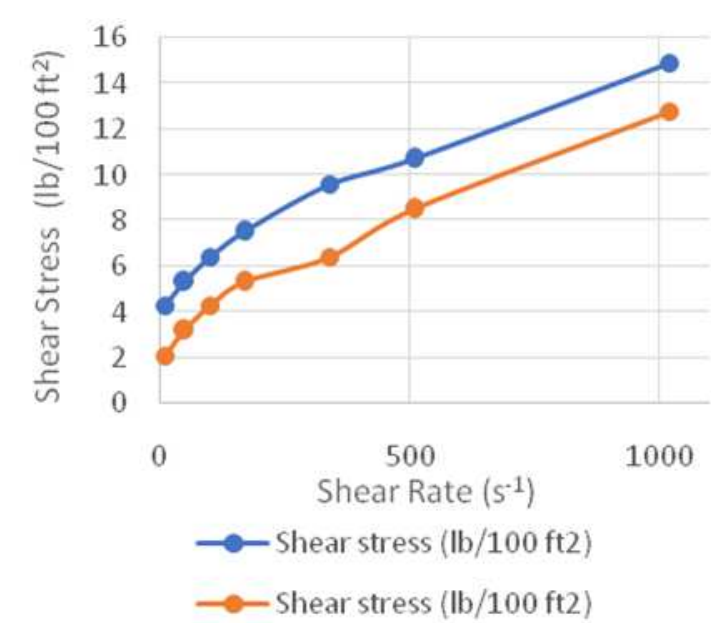

Fig. 8. Shear stress Vs shear rate curve for runorder2

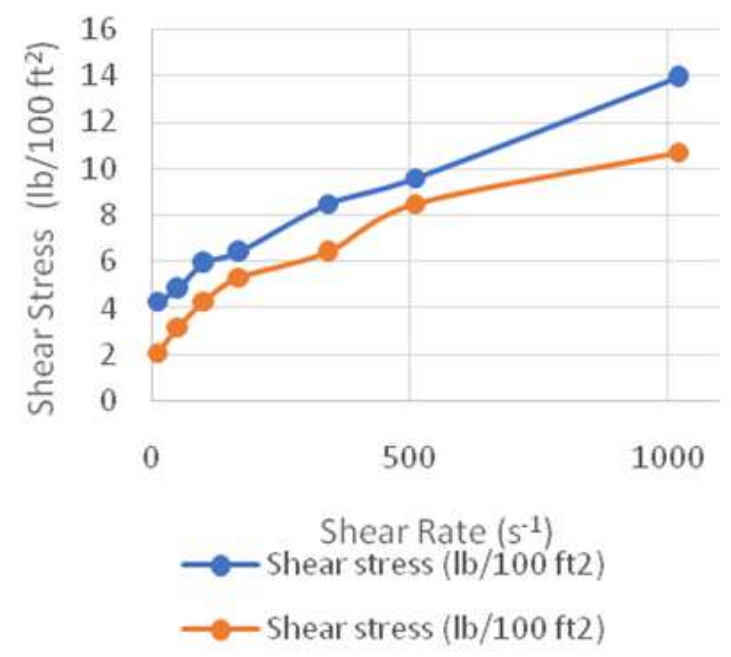

Fig. 9. Shear stress Vs shear rate curve for runorder3

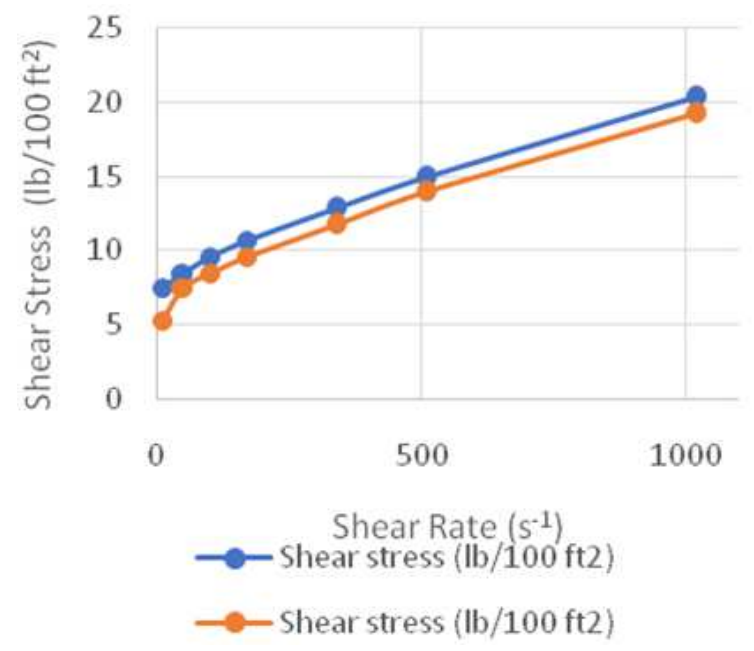

Fig. 10. Shear stress Vs shear rate curve for runorder4
Table 7. $\mathrm{P}^{\mathrm{H}}$ of formulated drilling mud samples

\begin{tabular}{ll}
\hline Sample & $\mathrm{P}^{\mathrm{H}}$ \\
\hline Water based mud & 10.80 \\
Runorder1 (diesel) & 10.55 \\
Runorder1 (limonene) & 10.50 \\
Runorder2 (diesel) & 10.20 \\
Runorder2 (limonene) & 10.50 \\
Runorder3 (diesel) & 10.26 \\
Runorder3 (limonene) & 10.79 \\
Runorder4 (diesel) & 10.65 \\
Runorder4 (limonene) & 10.90 \\
\hline
\end{tabular}

Table 8. Sand content of the formulated mud samples

\begin{tabular}{ll}
\hline Sample & Sand content (\%) \\
\hline Water based mud & 0.20 \\
Runorder1 (diesel) & 0.80 \\
Runorder1 (limonene) & 0.25 \\
Runorder2 (diesel) & 1.00 \\
Runorder2 (limonene) & 0.75 \\
Runorder3 (diesel) & 1.50 \\
Runorder3 (limonene) & 1.00 \\
Runorder4 (diesel) & 0.75 \\
Runorder4 (limonene) & 0.75 \\
\hline
\end{tabular}

The $\mathrm{P}^{\mathrm{H}}$ of the formulated mud samples are within the acceptable range. This will help prevent pipe and bit been corroded.

\section{Sand Content of Formulated Mud Samples}

The results of the sand content test are shown in Table 8 .

Nano-modified oil-in-water emulsion drilling mud sample formulated using runorder 1 with limonene as the dispersed phase has the lowest sand content while the sample formulated using runorder3 with diesel oil as the dispersed phase has the highest sand content as shown in Table 8. The sand contents of the formulations with limonene as the dispersed phase are lower compare to the ones with diesel as the dispersed phase using the same formulation RunOrder.

\section{Mud Filtration Test}

The filtration test was carried out at pressure of 100 psi for 30 minutes. The formulation using runorder 1 with limonene as the dispersed phase has the lowest filtrate volume while formulation using runorder4 with limonene as the dispersed phase has the highest filtrate volume. Also, the formulation using runorder2 has the lowest value of mud cake thickness while the formulation using runorder4 with limonene as the dispersed phase has the highest value of mud cake thickness as shown in Table 9 and Fig. 11 and 12. It can be inferred from Table 9 and Fig. 11 and 12 that formulation using runorder2 with limonene as the dispersed phase has a better filtration properties compared to other formulated samples. 


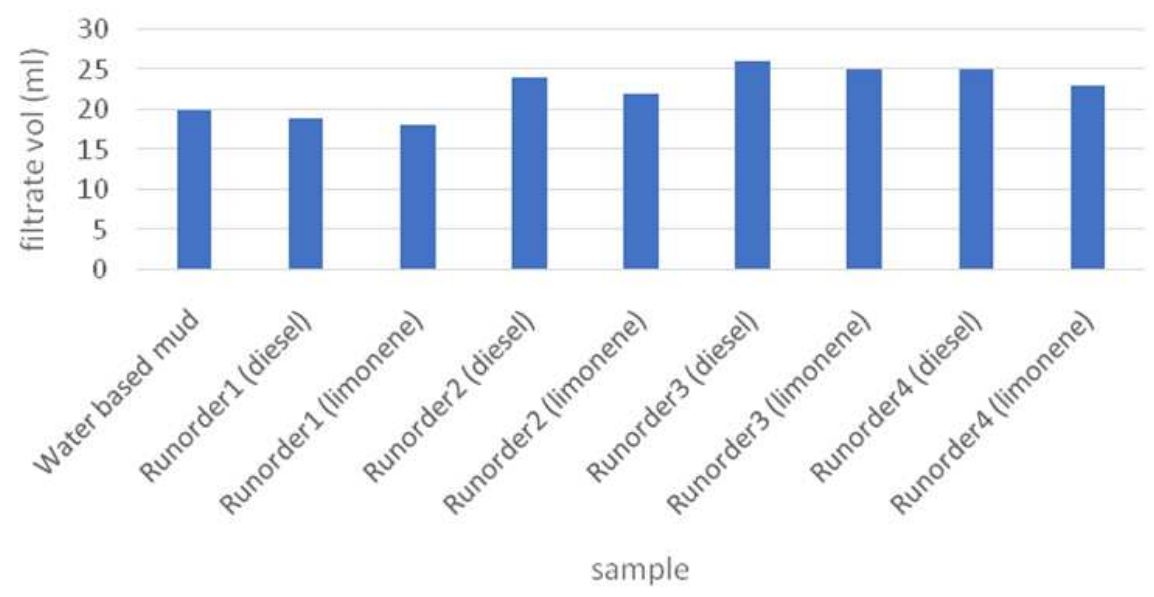

Fig. 11. Filtrate Volume (ml) for the formulated drilling mud

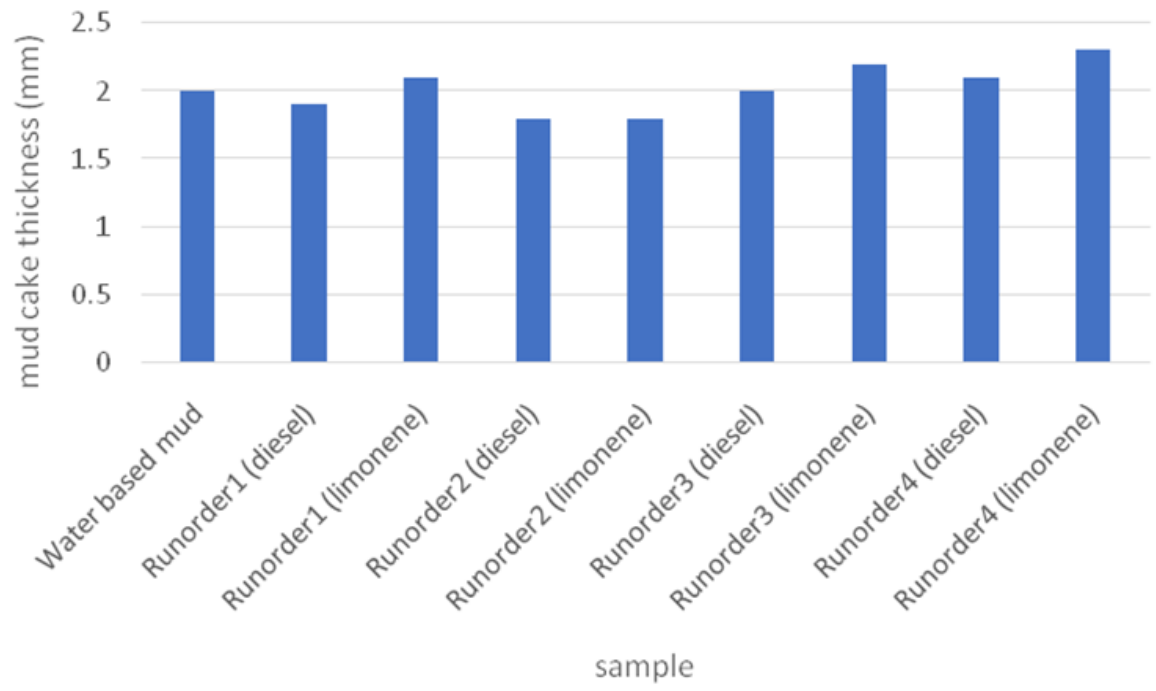

Fig. 12. Mud cake thickness (mm) for the formulated drilling mud

Table 9. Filtrate volume and Mud thickness for the formulated drilling mud

\begin{tabular}{lll}
\hline Sample & Filtrate $(\mathrm{ml})$ & Mud cake thickness $(\mathrm{mm})$ \\
\hline Water based mud & 20 & 2.0 \\
Runorder1 (diesel) & 19 & 1.9 \\
Runorder1 (limonene) & 18 & 2.1 \\
Runorder2 (diesel) & 24 & 1.8 \\
Runorder2 (limonene) & 22 & 1.8 \\
Runorder3 (diesel) & 26 & 2.0 \\
Runorder3 (limonene) & 25 & 2.2 \\
Runorder4 (diesel) & 25 & 2.1 \\
Runorder4 (limonene) & 23 & 2.3 \\
\hline
\end{tabular}

\section{Conclusion}

The formulated nano-modified oil-in-water emulsion drilling mud with limonene as the dispersed phase properties were compared with nano-modified oil-inwater emulsion drilling mud with diesel oil as the dispersed phase. While limonene has very good potentials as dispersed phase in the formulation of emulsion drilling mud when compared with diesel oil, based on the results obtained from the study, the following conclusions can be drawn:

- Limonene can replace diesel oil as the dispersed phase in the formulation of emulsion drilling mud 
- The formulated nano-modified emulsion drilling mud with limonene as the dispersed phase followed Herschel-Bulkley rheological Model with low gel strength and yield point which are desirable mud property for turbulent flow at low pump pressure for effective hole cleaning

- There is an improvement in the rheological and lubricating properties of the formulated nanomodified emulsion drilling mud with limonene as the dispersed phase

- There is reduction in filtration loss and mud cake compared to the conventional water-based drilling mud which will lead to reduction in torque and drag, reduction in pipe sticking, reduction in hole enlargement and less bit balling

- Formulation with $20 \mathrm{~mL}$ of limonene and $10 \mathrm{~g}$ of silicon oxide nanoparticle gives the best rheological and filtration loss properties

- The formulated nano-modified emulsion drilling mud with limonene as the dispersed phase is less toxic to human operators and readily biodegradable

The results from this work may be more encompassing for field application if the effects of aging and temperature variation are known for the formulated nano-modified emulsion drilling mud. Also, the effect of varying the barite content on the density of the formulated nano-modified emulsion drilling mud when further investigated may provide additional insight into the applicability of the proposed emulsion drilling mud.

\section{Acknowledgement}

The authors show their appreciation to Covenant University, Ota, Nigeria for providing financial assistance and necessary laboratory facilities for this research work.

\section{Author's Contributions}

O.M. Olaitan: Contributed to the conception, design, acquisition, analysis and interpretation of data and drafting of the article.

O.D. Orodu and A.B. Ehinmowo: Co-ordinated drafting and review of the article.

\section{Conflict of Interest}

The corresponding author confirms that all of the other authors have read and approved the article and no conflict of interest.

\section{References}

Al-Riyamy, K. and M.M. Sharma, 2004. Filtration properties of oil-in-water emulsions containing solids. SPE, 19: 164 -172. DOI: 10.2118/89015-PA
Amanullah, M.D., 2005. Physio-chemical characterisation of vegetable oils and preliminary test results of vegetable oil-based muds. Proceedings of the SPE/IADC Middle East Drilling Technology Conference and Exhibition, Sept. 12-14, Dubai, UAE. DOI: $10.2118 / 97008-\mathrm{MS}$

Anderson, M.J. and P.J. Whitcomb, 1998. Finding the Most Favorable Formulations, Chemical Engineering Progress, 94(4): 63-67.

Barlow, M.J. and P.F Kingston, 2001. Observations on the effects of barite on the gill tissues of the suspension feeder Cerastoderma edule (Linné) and the deposit feeder Macoma balthica (Linné). Marine Pollut. Bull., 42: 71-76. DOI: $10.1016 / \mathrm{S} 0025-326 \mathrm{X}(00) 00117-\mathrm{X}$

Caenn, R. and G.V. Chillingar, 1996. Drilling fluids: State of the art. J. Petroleum Sci. Eng., 14: 221-230. DOI: 10.1016/0920-4105(95)00051-8

Dosunmu, A. and J. Ogunrinde, 2010. Development of environmentally friendly oil based mud using palm oil and groundnut oil. Proceedings of the 34th Annual International Conference and Exhibition, Jul. 31-Aug. 7, Tinapa-Calabar, Nigeria. DOI: $10.2118 / 140720-\mathrm{MS}$

Ezejiofor, T.L.N., N.V. Eke, R.I. Okechukwu, R.N. Nwoguikpe and C.M. Duru, 2011. Waste to wealth: Industrial raw materials potential of peels of Nigerian sweet orange (Citrus sinensis). African J. Biotechnol., 10: 6257-6264.

Fadairo, A.A., A. Ameloko, G.A. Adeyemi, E. Ogidigbo and A. Oyakhire, 2012a. Environmental impact evaluation of a safe drilling mud. Proceedings of the SPE Middle East Health, Safety, Security and Environment Conference and Exhibition, Apr. 2-4, Abu Dhabi, UAE. DOI: 10.2118/152865-MS

Fadairo, A.A.., G.A.A. Adeyemi, A. Ameloko and O. Falode, 2012b. Modelling the effect of temperature on environmentally safe oil based drilling new technologies in the oil and gas industry 80 mud using artificial neural network algorithm. J. Petrol. Coal.

Jha, P.K., V. Mahto and V.K. Saxena, 2015. Effects of carboxymethyl cellulose and tragacanth gum on the properties of emulsion-based drilling fluids. Can. J. Chem. Eng., 93: 1577-1587.

DOI: $10.1002 /$ cjce. 22259

Kasiralvalad, E., 2014. The great potential of nanomaterials in drilling and drilling fluid applications. Int. J. Nano Dimens. 5: 463-471. DOI: 10.7508/ijnd.2014.05.006

Nasser, J., A. Jesil, T. Mohiuddin, M. Al-Ruqeshi and G. Devi et al., 2013. Experimental investigation of drilling fluid performance as nanoparticles. World J. Nano Sci. Eng., 3: 57-61.

DOI: $10.4236 /$ wjnse.2013.33008 
Njoku, V.I. and B.O. Evbuomwan, 2014. Utilization of essential oil and pectin extracted from Nigerian orange peels. Greener J. Chem. Sci. Technol., 1: 001-005. DOI: 10.15580/GJCST.2014.1.041414186

Paswan, B.K., R. Jain, S.K. Sharma, V. Mahto and V.P. Sharma, 2016. Development of Jatropha oil-inwater emulsion drilling mud system. J. Petrol. Sci. Eng., 144: 10-18. DOI: 10.1016/j.petrol.2016.03.002
Yue, Q. and B. Ma, 2008. Development and applications of solids-free oil-in-water drilling fluids. Petrol. Sci., 5: 153-158.

DOI: $10.1007 / \mathrm{s} 12182-008-0023-3$ 